These inquiries suggest that if treatment to influence bloodpressure is necessary at all after cerebral infarction the measures most likely to do good are those that maintain or raise blood-pressure rather than those that lower it, and the patients who most need treatment are the old people with disproportionately low pressures who suffer from symptoms of postural hypotension.

We support the statement that the intensity of the pressure rise for the individual is the important thing, not an arbitrary level used to define hypertension regardless of age, sex, and other factors that influence it (Pickering, 1955), and believe that a more precise study than any at present available should be made of the systemic blood-pressure in the survivors of cerebral infarction, and that the relationship of this pressure to life expectancy after stroke should be reassessed.

\section{Summary}

Comparison of mortality in survivors of strokes classified by systolic blood-pressure alone, diastolic blood-pressure alone, a complex of systolic and diastolic pressures, and pulse pressure alone, failed to provide convincing evidence of an adverse effect of hypertension on mortality after cerebral infarction. (The pressure levels accepted as hypertensive were systolic $180 \mathrm{~mm}$. $\mathrm{Hg}$ or more, diastolic $110 \mathrm{~mm}$. $\mathrm{Hg}$ or more). There is some evidence, however, that patients with high pressures have a lower mortality in the first two months after stroke than patients with low pressures.

We are indebted to Mrs. J. J. McCabe, Mrs. L. McCreight, and Mrs. E. Reid for help in compiling the statistical data, and to Mrs. V. Stewart and Miss M. J. Reid for the manuscript and tables.

\section{REFERENCES}

Adams, G. F. (1965). Brit. med. F., 2, 253.

- and Merrett, J. D. (1961). Ibid., 1, 309

Carter, A. B. (1963). Proc. roy. Soc. Med., 56, 483.

Car (1964). Cerebral Infarction. Pergamon Press, London.

Hamilton, M., Thompson, E. N., and Wisniewski, T. K. M. (1964).

Lancet, 1, 235 .
Hodge, J. V., McQueen, E. G., and Smirk, H. (1961). Brit. med. Y.,

Johnson, R. H., Smith, A. C., Spalding, J. M. K., and Wollner, L. (1965). Lancet, 1, 731

Leishman, A. W. D.' (1963). Ibid., 1, 1284.

Low-Beer, T., and Phear, D. (1961). Ibid., 1, 1303

Marshall, J. (1963). Proc. roy. Soc. Med., 56, 486

- (1964). Lancet, 1, 10.

- and Kaeser, A. C.' (1961). Brit. med. 7., 2, 73.

McKeown, F. (1965). Pathology of the Aged, p. 321. Butterworth, London.

Pickering, G. W. (1955). High Blood Pressure. Churchill, London.

Rosenheim, M. L. (1962). Proc. roy. Soc. Med., 55, 278.

Smirk, H., and Hodge, J. V. (1963). Brit. med. Ұ., 2, 1221.

\title{
Herpes Simplex Virus Skin Infection in Man Treated with Idoxuridine in Dimethyl Sulphoxide. Results of Double-blind Controlled Trial
}

\author{
F. O. MACCALLUM,* M.A., M.D., B.SC., M.R.C.P.; B. E. JUEL-JENSEN, $†$ M.A., B.M., CAND.MED.
}

Brit. med. F., 1966, 2, 805-807

The satisfactory results of Kaufman's experiments with idoxuridine in the treatment of herpetic keratitis in rabbits, and subsequent double-blind controlled treatment trials in acute herpetic keratitis in humans, indicated that this substance might be effective in treating other manifestations of herpes simplex virus infection in man if it could be brought to act in adequate concentrations at suitable times in the cycle of replication of the virus without damaging unaffected cells in adjacent or other tissues or organs.

Reports of failure to increase the normal rate of healing of skin lesions (cold sores) by application of $0.5 \%$ idoxuridine in ointment (Burnett and Katz, 1963 ; Juel-Jensen and MacCallum, 1964) showed that other methods were required to facilitate the action of idoxuridine on virus in cells of the skin. Percutaneous inoculation of a $0.1 \%$ aqueous solution of idoxuridine in a fine spray by means of a pressure-jet gun achieved a modicum of success (Juel-Jensen and MacCallum, 1965), but only a single treatment was practicable, and obviously this did not reach all infected cells. The increased rate of recovery was assumed to be due to a combination of a reduction in the number of virusinfected cells and the action of antibody. When recurrences subsequently occurred in several treated patients the lesions appeared at new sites-an uncommon happening in the natural history of the disease.

Idoxuridine is very insoluble in watery solution, and it therefore seemed that a solvent which would provide a higher con-

\footnotetext{
* Consultant Virologist, Radcliffe Infirmary, Oxford; University Lecturer in Virology, Oxford.

† Hospital Medical Officer, Radcliffe Infirmary, Oxford ; Medical Officer, University of Oxford Clinical Medical School.
}

centration and/or allow greater powers of penetration of the drug through the skin to the affected cells was required. We chose dimethyl sulphoxide. After this work began reports appeared of the use of a solution containing equal parts of $50 \%$ polyethylene glycol 4000 and water to obtain $0.9 \%$ idoxuridine for treatment of experimental keratitis in rabbits (Jawetz et al., 1965), and more recently Corbett et al. (1966) reported on the use of $0.1 \%$ idoxuridine in $1.4 \%$ polyvinyl alcohol in treatment of herpetic skin lesions in man.

The results of experiments in which primary herpes simplex virus intradermal infections in guinea-pigs were treated with varying concentrations of idoxuridine in different dilutions of dimethyl sulphoxide (Tomlinson and MacCallum, 1965) suggested that $5 \%$ idoxuridine in undiluted dimethyl sulphoxide might be effective in the treatment of recurrent herpetic skin lesions (cold sores) in volunteers. A double-blind controlled trial was organized in the same manner as our previous two trials.

\section{Methods}

The patients in the trial were drawn from the medical students of the Clinical School and from the staff of the Radcliffe Infirmary. Herpes sufferers reported as soon as possible and not later than 24 hours after the onset of the first symptoms. A careful history was taken, including information about the duration of previous attacks. A swab from the lesion was taken into virus transport medium and sent to the laboratory within an hour, and a sample of blood for antibody studies was collected. 
A $5 \%$ solution of idoxuridine in dimethyl sulphoxide was prepared, and this, and dimethyl sulphoxide alone, were distributed in aliquots (2-ml. amounts) in identical bijou bottles in random order. Experiments with small paintbrushes showed that about $1 \mathrm{ml}$. was required for application of an adequate amount of the solution to cover the lesion three times a day for three days, and each patient was provided with an autoclaved brush. Each bottle had a number for identification. The contents of the bottle were unknown to the patient and the observer. The same observer saw each patient daily and recorded details of the progress of the lesion. At the end of the three days the patient returned the bottle. The remaining $1 \mathrm{ml}$. of fluid provided an additional check that the patient had in fact used the substance.

\section{Results}

Sixteen patients participated, and five developed a lesion in a new site after a clear interval and were entered again. One patient (Case 15) developed a lesion in a new site while the old was still healing, and was entered as $15 \mathrm{~A}$ and treated with the same substance as in the concurrent attack, making 22 patient-attacks. One patient (Case 4) did not complete the trial. The lesions in 10 attacks were treated with active idoxuridine solution, in 11 with dimethyl sulphoxide. In all, the clinical diagnosis was certain, virus was isolated, and complement-fixing and neutralizing antibodies to herpes simplex virus were present. The results are set out in Table I. The average duration of the attack until arrest of lesion, leaving only a dry crust, was 1.2 days (S.E. \pm 0.20 ) in the group receiving idoxuridine, and 2.45 (S.E. \pm 0.56 ) in those receiving only dimethyl sulphoxide. The scabs had also gone after 3.5 days (S.E. \pm 0.53 ) in the former, and after 5.45 days (S.E. \pm 0.91 ) in the latter. The average normal duration of the attack, as estimated by the patients without treatment, was 9.8 and 9.55 days in the two groups. There was thus a shortening of the average duration of the attack of 6.3 days $(64 \%)$ for the idoxuridine-treated group, and 4.1 days ( $43 \%$ ) for the dimethyl sulphoxidetreated group, a difference of 2.6 days between the idoxuridine in the solvent and the solvent alone.

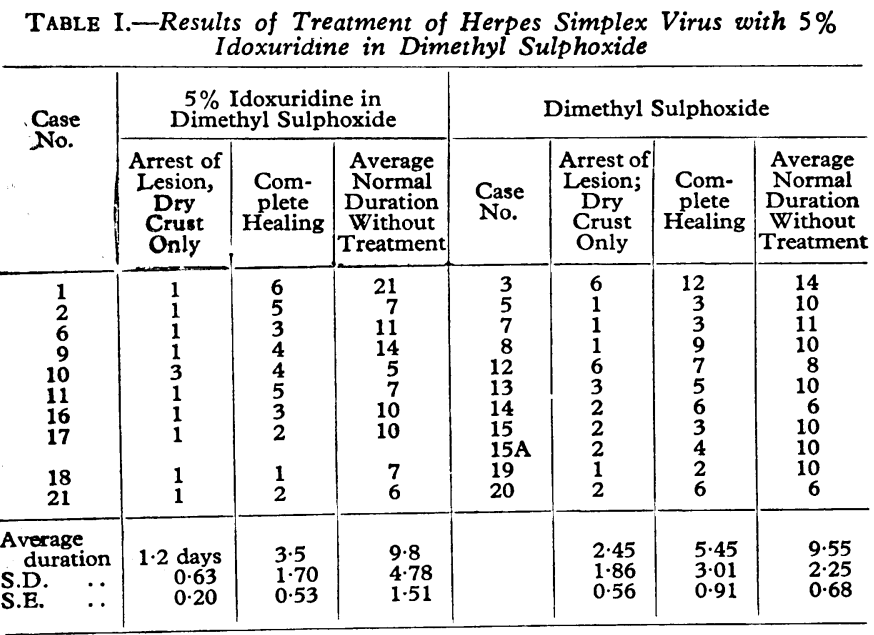

\section{Discussion}

The difference in the results between the three methods of application of idoxuridine which we have tested is seen in Table II. The methods of treatment are not comparable so far as the amount of idoxuridine applied is concerned, and it is quite possible that several injections with the spray gun might have been as effective as the solution of idoxuridine in dimethyl sulphoxide. Uncontrolled clinical observations on the effect of multiple injections on successive days on herpetic whitlows suggest that this may be so. In a very brief note Kaufman (1965) reported that in treating experimental herpetic keratitis in rabbits a solution of idoxuridine in dimethyl sulphoxide was much less effective per unit of drug concentration than was the comparable concentration of drug in saline. This was contrary to our observations in treating primary herpes simplex virus in guinea-pigs, in which the best results were obtained by $10 \%$ idoxuridine in undiluted dimethyl sulphoxide. The point is of questionable significance in treating skin infections by surface application when $0.1 \%$ idoxuridine in saline, the maximum concentration readily obtainable, is ineffective. Obviously, treating primary infection in a guinea-pig without antibody is a more severe test than treating recurrent herpetic skin lesions in man where neutralizing antibody is present, and the effect of lower concentrations of idoxuridine in weaker solutions of dimethyl sulphoxide and more frequent application, particularly in the early stages, are now being tested.

TABLE II.-Duration of Skin Lesions to Complete Healing in Three

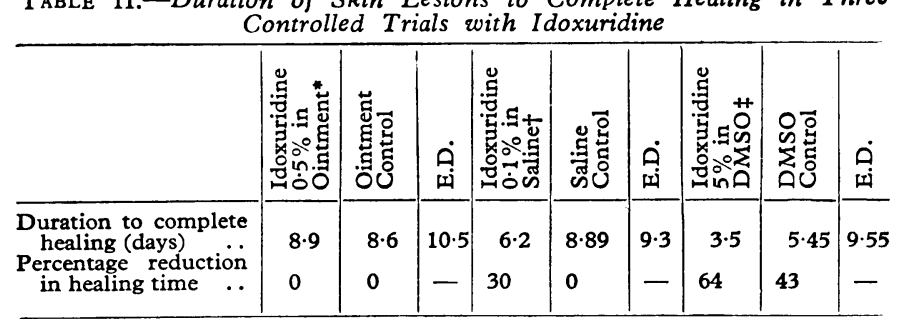

* Oiftment applied three times a day for duration of lesion.

t Spray gun-one inoculation.

E.D. = Expected duration of lesion.

Corbett et al. (1966) reported that a much more intensive schedule of application of $0.1 \%$ idoxuridine in $1.4 \%$ polyvinyl alcohol of every five minutes for one hour, every hour for 12 hours, and every two hours during the day for four days, was followed by healing in average of 5.7 days compared with 12.5 in their placebo group, a reduction of $55 \%$. The practicability of treatment applied at such frequent intervals for so long becomes doubtful except in hospital practice. Dimethyl sulphoxide causes a slight tingling or burning sensation when applied to the skin, and this inflammatory reaction probably increases the amount of antibody in the intercellular spaces and so aids healing.

Certain toxic effects have been reported to occur after application to the skin of very large amounts of dimethyl sulphoxide. The very small amount $(1 \mathrm{ml}$.) of dimethyl sulphoxide used in this investigation was thought to be of no consequence in view of the long history of its use as a solvent in industry without harmful effects. Idoxuridine interferes with the formation of deoxyribonucleic acid in actively dividing cells, and this preparation must not be given to pregnant women.

No recurrences in the same site have occurred over the succeeding six months in the group treated with idoxuridine, when an average of 1.7 recurrences per patient (as judged by past histories) could have been expected. Recurrence in a new site occurred within six months in two of the 10 patients treated with idoxuridine (an average of 1.5 recurrences might have been expected in these two patients). Recurrences in four patients appeared in the same site within six months in the group (11) treated with dimethyl sulphoxide alone (expected average 3.3 per patient in the four only). Six patients had no recurrence (expected average 1 per patient). It thus looks as though idoxuridine in dimethyl sulphoxide not only promotes healing but also may prevent recurrence at the same site if the lesion is treated early. The low recurrence rate in the group treated with dimethyl sulphoxide may be due to the early action of antibody because of the local inflammation.

Insufficient cases of herpetic whitlow have been available for a controlled trial, but our impression is that three patients with this painful condition have benefited from treatment with the 
solution described above. The amount of herpes virus recovered in successive cultures decreased more rapidly and the virus disappeared more quickly than in previous patients who had had no idoxuridine.

\section{Summary}

Patients with 21 attacks of herpes of the face participated in a double-blind controlled trial to test the effect of idoxuridine in the form of a $5 \%$ solution in dimethyl sulphoxide. The solution was applied with a paintbrush three times a day for three days; a total volume of $1 \mathrm{ml}$. was used. In 10 patients receiving the idoxuridine solution there was an average shortening of the expected duration of the lesion of 6.3 days (or $63 \%$ ) and an average shortening of two days compared with those treated with dimethyl sulphoxide alone. This was the greatest reduction achieved so far.
The results indicate that it should be possible to obtain a suitable preparation of idoxuridine which will be of therapeutic value in those in whom recurrent attacks of herpes simplex virus skin infection usually persist for seven days or longer.

Our thanks are due to Dr. T. A. Turnbull, of Smith Kline and French Laboratories Ltd., for the supply of idoxuridine; to Mr. Ivor Chin, F.I.M.L.T., for his help with the virus cultures; to Miss Craig, of the Pharmacy, the Radcliffe Infirmary; and, not least, to our patients for their intelligent cooperation.

\section{REFERENCES}

Burnett, J. W., and Katz, S. L. (1963). F. invest. Derm., 40, 7 Corbett, M. B., Sidell, C. M., and Zimmerman, M. (1966). F. Amer. med. Ass., 196, 441.

Jawetz, E., Schultz, R., Coleman, V., and Okumoto, M. (1965). F. Immunol. 95, 635 .

Juel-Jensen, B. E., and MacCullum, F. O. (1964). Brit. med. F., 2, 987. (1965), Ibid. 1,901

Kaufman, H. E. (1965). Ann. N.Y. Acad. Sci., 130, 168

Tomlinson, A. H., and MacCallum, F. O. (1965). 'Unpublished.

\section{Medical Memoranda}

\section{Unusual Fatal Brain Injury Due to Knitting-needle}

\section{Brit. med. F., 1966, 2, 807-808}

Penetrating injuries of the skull are relatively rare. "Fatal wounds of the skull and brain, such as penetrating stab wounds ... can occur with little or no external evidence of injury" (Helpern, 1946). Published cases of penetrating head injuries (Helpern, 1946 ; Louttit, 1954) show that the patient may be able to continue his pursuits for some time after the incident, and may not lose consciousness after a deep penetrating injury to the brain (Dawson, 1954).

The following case is of a 13-month-old male infant who died three days after what was thought to be a trivial penetrating injury on the back of the neck. As the cause of death was unknown the case was reported to the coroner, who asked for a post-mortem examination.

\section{CAse Report}

A male infant of 13 months was admitted to hospital in coma three days before his death. The mother gave the history that she was changing the child's napkin and had set him on the arm of a leather armchair situated about $2 \mathrm{ft}$. $(61 \mathrm{~cm}$.) from the wall; while airing the clean napkin in front of the fire she saw the child slip off the side of the chair between the wall and the chair. A knitting-bag had previously been stowed at the side of the chair so that it would be out of harm's way; one of the knitting-needles (a No. 8 steel needle) had been left pointing upwards skewered through a ball of wool. As the mother picked up the child he began to cry, and she noticed a steel knitting-needle protruding from the folds in the back of the child's dress: she pulled the needle and found that it had penetrated the skin of his neck. After removal of the needle she saw a small bleeding-point on the back of his neck; she thought the wound was superficial. Within a few minutes the child ceased crying and lost consciousness. The doctor was summoned and he immediately took the child to the local hospital, where an emergency tracheostomy was performed to relieve cyanosis and laryngeal stridor; the baby was then transferred to a paediatric centre.

On examination he was unconscious; the right arm and leg were flaccid and paralysed; the pupils were equal but did not react to light ; there was a small superficial wound low down on the right side of the neck. $X$-ray examination of the skull did not reveal any definite lesion.
An electroencephalogram showed diffused abnormality with a focus on the right side. Lumbar puncture revealed uniformly bloodstained fluid. Burr-holes were performed and these showed that the brain was oedematous: an air ventriculogram did not reveal an abnormality.

His condition gradually deteriorated; all his limbs became spastic and he died three days after his admission to hospital. The necropsy was performed on the day after death. The findings were as follows :

Externally.-A clean, well-nourished infant. The right pupil was larger than the left. There was a small puncture wound $(2 \mathrm{~mm}$. diameter) on the right side of the lower part of the back of the neck (Fig. 1).



FIG. 1.-Back of the head, neck, and shoulders of the infant at necropsy. There is a small haemorrhagic puncture wound (arrowed) on the lower part of the neck on the right side.

Internally.-In the subcutaneous tissues of the neck below the skin wound there was a small amount of haemorrhage, which extended up to a puncture wound in the right occipital bone. The inner table of the right squamous occipital bone showed a 1-cin. area of haemorrhage in the periosteum surrounding an elevated flap of bone about $4 \mathrm{~mm}$. in diameter. There was a linear laceration $(5 \mathrm{~mm}$. long) of the dura mater on the lateral side of the left posterior clinoid process. The brain showed general oedema. 